\title{
Linguistic Ecology of North Mara "Languages": A Comparative Study of Sound System Among the Selected "Languages"
}

\author{
Boniphace Morango Alphonce \\ Department of Kiswahili Language and Literature, University of Dar es Salaam, Dar es Salaam, Tanzania
}

Email address:

aboniphace26@gmail.com

\section{To cite this article:}

Boniphace Morango Alphonce. Linguistic Ecology of North Mara "Languages": A Comparative Study of Sound System Among the Selected "Languages". International Journal of Language and Linguistics. Vol. 6, No. 3, 2018, pp. 80-89. doi: 10.11648/j.ij11.20180603.14

Received: May 9, 2018; Accepted: May 25, 2018; Published: June 12, 2018

\begin{abstract}
Language sounds are sounds which construct meaningful phrases in languages. Although human beings produce many sounds of different types, human language uses only a certain number and types of sounds. Sounds of languages are of two types; either consonants or vowels due to articulatory system. The studied North Mara "languages" are Kurya, Simbiti, Kiroobha, Sweeta, Kabwa, Suba1, Kine and Kenye, There are two perspectives relating to North Mara "languages": In one perspective, these languages are regarded as similar and related to each other while in the other perspective the languages are regarded as different. The article focuses on the comparison of sound system in North Mara "languages". According to data obtained, there are several syntactical criteria discussed: these are compensatory lengthening, deletion and minimal pairs. The study was led by "Comparative and Historical Linguistics" theory in portraying the relationship of "languages" being studied. The study used group discussion method to obtain data that gives similarities and differences of investigated "languages". The results obtained from the research prove that there is a great similarity among the investigated "languages" in the case of sound system. Hence, linguistically these "languages" are more like dialects that relates closely to each other and are not independent languages as are seen in sociolinguistics perspective.
\end{abstract}

Keywords: Comparisons, Similarities and Differences, Consonants and Vowels

\section{Introduction}

The article is generally deals with sound system, one aspect of phonology that was compared in North Mara "languages". This article is just a part of the larger data collected in the field when investigating North Mara "languages" for the purpose of completing $\mathrm{PhD}$ study. The "languages" investigated were Kurya, Simbiti, Kiroobha, Sweeta, Kabwa, Suba1, Kine and Kenye. In the article various sound segments were described in consonants and vowels, in vowels three phonological criteria were discussed: compensatory lengthening, deletion and minimal pairs. This is to show how these "languages" relate to each other that means, to determine the similarities and differences in the case of sound system as shown in the "languages". The article was led by "Historical and Comparative Linguistics" theory which advocates on the investigation on relatedness languages, tracing back their origins in order reconstruct a new language, it was first developed by Jones (1786). The article also used group discussion method to obtain the data which were analyzed. The article is of five sections; introduction, theory, methods, results and conclusion.

The article is mainly concerned with sound system, one aspect of phonology that was compared in North Mara "languages". This article is just a part of the larger data collected in the field when investigating North Mara "languages" for the purpose of completing $\mathrm{PhD}$ study. The "languages" investigated are Kurya, Simbiti, Kiroobha, Sweeta, Kabwa, Suba1, Kine and Kenye. In the article, various sound segments have been described to show how these "languages" relate to each other (to show their relationship), by determining the similarities and differences in the case of sound system as shown by these "languages". The article is of five sections; introduction, methods, results and conclusion. 


\section{Theoretical Framework: Historical and Comparative Linguistics Theory}

The study was guided by Historical and Comparative Linguistics theory. Historical and comparative linguistics is a study that combines two disciplines. However, in this article, the terms are treated as a single field of study, but it should be noted that differ considerably with respect to their goals and methods. The historical linguistics (also called diachronic linguistics) deals with the scientific study of language change over time, investigation of language change and development. Its results are directly relevant to comparative linguistics. This can be for one of the following three reasons; 1) because they stem from some common source; 2) because they influenced each other during periods of intensive language contact. The other discipline is the comparative linguistics (originally comparative philology) which is concerned with comparing languages to establish their historical relatedness. The theory was established by Jones (1786) in his lecture on Sanskrit language in Asian language community [2].

One of the fundamental methods of comparative linguistics is to compare phonological systems, morphological systems, syntax and the lexicon of two or more languages using strategies such as the comparative method. In principle, every difference between two related languages should be explicable to a high degree of plausibility, and systematic changes [3, 4].

[1] states that comparative method is the core in Comparative and Historical Linguistics theory. Comparative method is mainly used in examining and analyzing the language development by comparing two or more languages that originate from the common source by tracing back their origin. The method was first developed in the $19^{\text {th }}$ century, its founders were Franz Bopp (1791-1867) as in 1816 used it for correspondences between verbal system of Sanskrit, Greek and Latin to prove their genetic relatedness and Jakob Grimm (1785-1863 established the sound correspondences between the consonants of Germanic.

\section{Methodologies}

The research was conducted in North of Mara region where the researcher used native speakers of North Mara "languages". Speakers of different "languages" came from various areas: Kurya from Rosana and Nyamwaga villages, Kabwa from Kirumi Centre and Mizami villages, Kiroobha from Bweri and Nyabange villages, Suba1 from Muharango village, Kine from Randa village, Simbiti from Nyanchabhakenye and Kuruya villages, Sweeta from Gamasara village and Kenye from Surubu and Nyanjagi villages. The area was selected because of having many complex languages due to its relatedness which caused ambiguity to linguists and speakers themselves of not knowing which are dialects and which are languages. In addition, most of languages in the area were not studied, there was no thorough linguistics research conducted to North Mara "languages". Therefore, the area real needed a thorough investigation. Moreover, the villages were selected because most of the people who live there are the native speakers of their "languages", and we also believe that there is no great interference with other speech communities around the area. Thus, the targeted respondents are not affected by nearby communities, such as Luo, Jita etc.

The research used a sample of 200 words which were written in alphabetical order of Swahili language and their synonyms written in North Mara "languages". The words used were core vocabularies which were distributed to various groups of respondents in all 8 investigated "languages". The data collected from the list of 200 words satisfied the study as the core vocabularies were compared to all 8 languages. The investigated "languages" were 8 due to various reasons; firstly, they are the only "languages" found in the area of research among those suggested by the researcher. Secondly, these are the "languages" which seem be controversial to the area, to extent of not distinguishing what are dialects and what are languages among these "languages".

In this article, group discussion technique was used aiming at obtaining the similarities and differences in the sound system in the investigated "languages". The respondents were distributed in different groups people, aged from 30 and above, these seem to have language command. Each group had 20 respondents with gender equality. These groups discussed various issues pertaining to sounds: consonants and vowels whereby three things were discussed in vowels; compensatory lengthening, deletion and minimal pairs. During the discussion, respondents were recorded and the conclusions reached after writing in a special form provided what were discussed. Through this technique, the researcher was free to ask questions that could benefit the research.

\section{Results and Discussion}

The sound system is very essential in communication. There are many types of sounds that are used to present the feelings, emotional and aspiration in human life [6]. The sound system in North Mara "languages" ${ }^{1}$ has been investigated basing on consonants and vowels (in vowels, three things were investigated; compensatory lengthening, deletion and minimal pairs) as hinted above. Elaboration of sound system as found in the field is as follows:

\subsection{Consonants}

Phonetically, a consonant is a speech sound that is articulated with complete or partial closure of the vocal tract [10], [8]. Supporting Massamba's view [5] insist that the closure mentioned here should be that used in articulating fricatives and there to in the middle of the mouth cavity.

According to the data obtain, North Mara "languages" have various consonant sounds which look similar or different from one language to another. Table 1 illustrates

1 The word language is written with inverted comma because of uncertainty of whether what are investigated are real independent languages or dialects of same language. 
how these sounds appear in respective "languages". The table also shows numbers of consonants available in each "language". As it is seen there are "languages" having 14 or 15 consonants and others up to 16 . Moreover, the proto-
Bantu consonants have been listed aside to be compared with North Mara "languages". The table shows that there are sounds which are not found in North Mara "languages" although the same sounds are in other Bantu languages.

Table 1. The Consonants of North Mara "Languages" and Proto-Bantu.

\begin{tabular}{|c|c|c|c|c|c|c|c|c|c|c|}
\hline Na. & Proto-Bantu & Sound & Kurya & Simbiti & Kiroobha & Sweeta & Kabwa & Suba1 & Kine & Kenye \\
\hline 1 & $*_{\mathrm{p}}$ & $\mathrm{p}$ & - & - & - & - & - & - & - & - \\
\hline 2 & $* b$ & $\mathrm{~b}$ & - & - & - & - & - & - & $\mathrm{b}$ & - \\
\hline 3 & & $\beta$ & $\beta$ & $\beta$ & $\beta$ & $\beta$ & $\beta$ & $\beta$ & $\beta$ & $\beta$ \\
\hline 4 & $*_{\mathrm{t}}$ & $\mathrm{t}$ & $\mathrm{t}$ & $\mathrm{t}$ & $\mathrm{t}$ & $\mathrm{t}$ & $\mathrm{t}$ & $\mathrm{t}$ & $\mathrm{t}$ & $\mathrm{t}$ \\
\hline 5 & $* d$ & d & - & - & - & - & - & - & - & - \\
\hline 6 & $* \mathrm{c}$ & $\check{c}$ & $\check{c}$ & - & - & $\check{c}$ & - & $\check{c}$ & $\check{c}$ & - \\
\hline 7 & $* \mathrm{j}$ & $\dot{j}$ & - & - & - & - & f & - & - & - \\
\hline 8 & ${ }^{*} \mathrm{k}$ & $\mathrm{k}$ & $\mathrm{k}$ & $\mathrm{k}$ & $\mathrm{k}$ & $\mathrm{k}$ & $\mathrm{k}$ & $\mathrm{k}$ & $\mathrm{k}$ & $\mathrm{k}$ \\
\hline 9 & $*_{\mathrm{g}}$ & $\mathrm{g}$ & - & - & - & - & $\mathrm{g}$ & $\mathrm{g}$ & $\mathrm{g}$ & - \\
\hline 10 & & $\gamma$ & $\gamma$ & $\gamma$ & $\gamma$ & $\gamma$ & - & $\gamma$ & $\gamma$ & $\gamma$ \\
\hline 11 & & $\mathrm{~s}$ & $\mathrm{~s}$ & $\mathrm{~s}$ & $\mathrm{~s}$ & $\mathrm{~s}$ & $\mathrm{~s}$ & $\mathrm{~s}$ & $\mathrm{~s}$ & $\mathrm{~s}$ \\
\hline 12 & & $\check{\mathrm{s}}$ & - & $\check{s}$ & $\check{\text { s }}$ & - & - & - & - & $\check{\mathrm{s}}$ \\
\hline 13 & & $\mathrm{~h}$ & $\mathrm{~h}$ & $\mathrm{~h}$ & $\mathrm{~h}$ & $\mathrm{~h}$ & $\mathrm{~h}$ & $\mathrm{~h}$ & $\mathrm{~h}$ & $\mathrm{~h}$ \\
\hline 14 & $*^{m} \mathrm{~m}$ & $\mathrm{~m}$ & $\mathrm{~m}$ & $\mathrm{~m}$ & $\mathrm{~m}$ & $\mathrm{~m}$ & $\mathrm{~m}$ & $\mathrm{~m}$ & $\mathrm{~m}$ & $\mathrm{~m}$ \\
\hline 15 & $* \mathrm{n}$ & $\mathrm{n}$ & $\mathrm{n}$ & $\mathrm{n}$ & $\mathrm{n}$ & $\mathrm{n}$ & $\mathrm{n}$ & $\mathrm{n}$ & $\mathrm{n}$ & $\mathrm{n}$ \\
\hline 16 & $* \mathrm{n}$ & $\mathrm{n}$ & $\mathrm{n}$ & $\mathrm{n}$ & $\mathrm{n}$ & $\mathrm{n}$ & $\mathrm{n}$ & $\mathrm{n}$ & $\mathrm{n}$ & $\mathrm{n}$ \\
\hline 17 & & $\eta$ & $\eta$ & $\eta$ & $y$ & y & $\eta$ & $\eta$ & $\eta$ & $\eta$ \\
\hline 18 & & $\mathrm{r}$ & $\mathrm{r}$ & $r$ & $\mathrm{r}$ & $\mathrm{r}$ & $r$ & $r$ & $\mathrm{r}$ & $\mathrm{r}$ \\
\hline 19 & & w & W & W & w & w & w & w & w & w \\
\hline 20 & & $\mathrm{y}$ & $\mathrm{y}$ & $\mathrm{y}$ & $\mathrm{y}$ & $\mathrm{y}$ & $\mathrm{y}$ & $\mathrm{y}$ & $\mathrm{y}$ & $\mathrm{y}$ \\
\hline Total & 11 & 20 & 14 & 14 & 14 & 14 & 14 & 15 & 16 & 14 \\
\hline
\end{tabular}

According to the list of consonants presented in the table, it is obvious that some of the consonants used in other Bantu languages are not used by these North Mara "languages". The data shows that the consonants used with these "languages" show great similarities, as so many consonants appear in the words used by these "languages". Despite, the similarities shown, there are few differences to some "languages" which can not affect the great similarities shown.

In these "languages" 12 consonants out of 16 are similar in all 8 "languages". Such consonants are $[\beta, t, k, s, h, m, n, y$, $\mathrm{n}, \mathrm{r}, \mathrm{w}, \mathrm{y}]$. The similarities shown is equal to $85.7 \%$ in all "languages", that means if the sound is there it cuts across the "languages" and if it misses is for all "languages" too.

There are sounds which appear only to some "languages", for example sound $/ \mathrm{b} /$ appears to some words of Kine "language". The data shows that other "languages" use sound $/ \beta /$, however, "languages" which use /b/ like Kine use $/ \beta /$ in most of their words. Therefore, some "languages" use both sounds, although are few.
From the data, sounds such as $/ \check{\mathbf{c}} /$ and $/ \check{\mathbf{s}} /$ are used in different "languages". Sound / $/$ / appears in four "languages" namely; Kurya, Sweeta, Suba and Kine. Sound / ̌s/ appears in three "languages" which are Simbiti, Kiroobha and Kenye. The two sounds give slight differences to words in case of articulation although the meaning of words remain the same, in other words a single word can be articulated differently and the speakers still understand to each other. The main reason for these differences is just self identification of speakers of a particular "language", they just isolate from other speech communities by articulating differently.

In the table above also appears the issue of voicing,

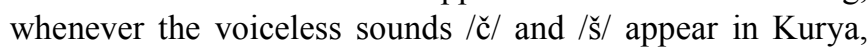
Simbiti, Kiroobha, Sweeta, Suba, Kine and Kenye they become voiced sound / $\mathbf{J} /$ in Kabwa "language". This happens in the same word with the same meaning, the main reasons for this might be generic relatedness and effect of coastal languages. Observe the two examples on table 2 and 3 below:

Table 2. The uses of sounds $/ \check{c} /,|\breve{s} /,| \mathrm{J} /$.

\begin{tabular}{llllll}
\hline Pre-Prefix & Stem & "Languages" & Pre-Prefix & Stem & "Languages" \\
\hline i- & $n c h$ oke & Kurya & e- & njuki & Kabwa \\
i- & $n s h$ oke & Simbiti & i- & nchoke & Suba1 \\
i- & $n s h$ oke & Kiroobha & i- & nchoke & Kine \\
i- & $n c h$ oke & Sweeta & i- & bshoke & Kenye \\
\hline
\end{tabular}

Table 3. The uses of sounds $/ \check{c} /, / \check{s} /, / J /$.

\begin{tabular}{|c|c|c|c|c|c|c|c|c|}
\hline Pre-Prefix & Prefix & Stem & "Languages" & Pre-Prefix & Prefix & Stem & "Languages" & Glossary \\
\hline $\mathrm{a}$ & $m a$ & choki & Kurya & $\mathrm{a}$ & $m a$ & joya & Kabwa & \multirow{4}{*}{ feathers } \\
\hline $\mathrm{a}$ & $m a$ & shoya & Simbiti & $\mathrm{a}$ & $m a$ & choki & Suba1 & \\
\hline $\mathrm{a}$ & $m a$ & shoya & Kiroobha & $\mathrm{a}$ & $m a$ & choya & Kine & \\
\hline $\mathrm{a}$ & $m a$ & choha & Sweeta & $\mathrm{a}$ & $m a$ & shoya & Kenye & \\
\hline
\end{tabular}


The other sound is /g/ which appears in few "languages", the data shows that it appears in three "languages" only: Kabwa, Suba and Kine. The other five "languages use sound $/ \gamma /$. However, in those three "languages"; two of them use both $/ g /$ and $/ \gamma /$ sounds. Therefore, Kabwa is the only "language" which does not use the sound $/ \gamma /$ completely;

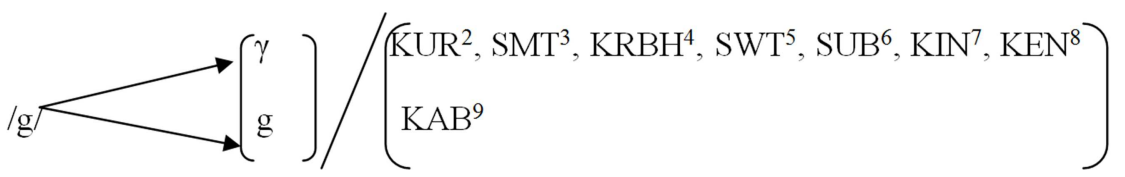

Figure 1. Formulated rule.

The formula above states that sound $/ \mathrm{g} /$ becomes sound $/ \gamma /$ when is used with the "languages" such as Kurya, Simbiti, Kiroobha, Sweeta, Suba1, Kine and Kenye. The same sound /g/ becomes /g/ when used only with Kabwa "language".

Many sounds which are used in these "languages" come from proto-Bantu sounds, as 9 sounds appeared in the uses of investigated "languages". Such sounds are $*_{\mathrm{b}}, *_{\mathrm{t}}, *_{\mathrm{c}}, *_{\mathrm{j}},{ }^{*} \mathrm{k}$, $*_{\mathrm{g}}, *_{\mathrm{m}}, *_{\mathrm{n}}$ and $*_{\mathrm{n}}$. There are only two proto-Bantu sounds which are not used in North Mara "languages", these are *p and $* \mathrm{~d}$. However, the sound $/ \mathrm{d} /$ which appears here is the result of assimilatory processes by the nasal $(\mathrm{N})$ being articulated together with the consonant which comes before it. In these "languages", when the sound $[\mathrm{r}]$ is preceded by the nasal [N] changes to [d], therefore, appears in uses as [nd] for some words. We can have the rule as:

$$
/ \mathrm{r} / \rightarrow[\mathrm{d}] / \mathrm{n}
$$

instead it uses sound $/ \mathrm{g} /$ in the same words where other "languages" use $/ \mathrm{g} /$. The data shows that almost 7 "languages" look similar as they all use /g/ sound and become different from Kabwa language which uses $/ \gamma /$. Here we can formulate a rule as:
In fact, this proves that these "languages" relate closely to each other, as 9 proto-Bantu sounds out of 11 look similar in all 8 "languages". This is equal to $81.8 \%$. Moreover, those two proto-Bantu sounds which are not used in all "languages", add the relationships among these "languages".

There are sounds which did not appear in North Mara "languages" in general, that means they are not used to these "languages". According to international sound system known as "International Phonetic Alphabet" (IPA) that illustrates the sounds to be used in various languages, these sounds [1, $\partial, p$, $\theta, \mathrm{f}, \mathrm{v}$, and $\mathrm{z}]$ are not used completely by North Mara "language" speakers. This evidence also indicates that these "languages" real relate to each other. The missing 7 sounds cut-across all "languages". One might say that they come from common ancestor/single source. Table 4 below shows place and manner of articulation of consonants in North Mara "languages".

Table 4. Consonants of North Mara "Languages".

\begin{tabular}{|c|c|c|c|c|c|c|}
\hline Manner of Articulation & Place of Articulation & Bilabial & Alveolar & Palato-alveolar & Velar & Glottal \\
\hline Plosives & & $\mathrm{b}$ & $\mathrm{t}[\mathrm{nt}][\mathrm{nd}]$ & & $\mathrm{k}[\mathrm{nk}] \mathrm{g}[\mathrm{ng}]$ & \\
\hline Affricates & & & & $\check{c}[n c ̌] J[n f]$ & & \\
\hline Fricatives & & $\beta$ & š[nš] s[ns] & $\gamma$ & & $\mathrm{h}$ \\
\hline Nasals & & $\mathrm{m}$ & $\mathrm{n}$ & $\mathrm{n}$ & $\eta$ & \\
\hline Laterals & & & $\mathrm{r}$ & & & \\
\hline Approximants & & w & & $\mathrm{y}$ & & \\
\hline
\end{tabular}

The table above illustrates the consonants of North Mara "languages" indicating the whole process of articulation which includes place and manner of articulation.

The data collected show that in these languages there are many words which are in nasal clusters; that is, the nasal consonant $(\mathrm{N})$ being followed by the consonants. In the clusters, the nasal consonant is forced to be articulated in the place of the consonant, these clusters are [mb, nt, nd, $\mathrm{nk}, \mathrm{ng}$, nč, nf, ns, nš, nj].

The clusters found in these "languages" are the result of two phonological processes: firstly, the nasal assimilation, the nasal consonant being forced to be articulated together with the consonant in its place of articulation. Secondly, is the process of fossilization, where the nasal $(\mathrm{N})$ which drops the vowel is articulated as a part of the stem of the word. The process causes vowel lengthening before the nasal $(\mathrm{N})$, the lengthening happens during articulation process, although does not appear in orthography. Observe the consonants clusters in table 5 . This $[\mathrm{N}]$ symbolizes nasal consonants.

Table 5. Consonants Clusters.

\begin{tabular}{|c|c|c|c|c|c|c|c|c|c|}
\hline \multirow{2}{*}{ Namba } & \multirow{2}{*}{ Sound } & \multicolumn{3}{|l|}{ Word } & \multirow{2}{*}{ Final Vowel } & \multirow{2}{*}{ Arrow } & \multirow{2}{*}{ Orthography } & \multirow{2}{*}{ Spoken } & \multirow{2}{*}{ Glossary } \\
\hline & & Pre-Prefix & Prefix & Stem & & & & & \\
\hline 1. & $/ \mathrm{mb} /$ & - & - & /gha-Nb- & $\mathrm{a}$ & $\rightarrow$ & gha [mba] & [raamba] & Speak \\
\hline 2. & /nt/ & o- & mo- & -Nto & - & $\rightarrow$ & omo [onto] & [omonto] & Person \\
\hline 3. & /nd/ & e- & - & -Nra & - & $\rightarrow$ & e [nda] & [eenda] & Stomack \\
\hline 4. & /nk/ & e- & - & -Nke & - & $\rightarrow$ & e [nke] & [eenke] & Small \\
\hline
\end{tabular}




\begin{tabular}{|c|c|c|c|c|c|c|c|c|c|}
\hline \multirow{2}{*}{ Namba } & \multirow{2}{*}{ Sound } & \multicolumn{3}{|l|}{ Word } & \multirow{2}{*}{ Final Vowel } & \multirow{2}{*}{ Arrow } & \multirow{2}{*}{ Orthography } & \multirow{2}{*}{ Spoken } & \multirow{2}{*}{ Glossary } \\
\hline & & Pre-Prefix & Prefix & Stem & & & & & \\
\hline 5. & $/ \mathrm{ng} /$ & o- & mo- & gho-Ngo & - & $\rightarrow$ & 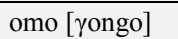 & [omoyoongo & backbone \\
\hline 6. & /nč/ & i- & - & -Nchoka & - & $\rightarrow$ & i [nčoka] & [inčoka] & Snake \\
\hline 7. & $/ \mathrm{nJ} /$ & e- & - & -Njoka & - & $\rightarrow$ & e [nfoka] & [enfoka] & Snake \\
\hline 8. & $/ \mathrm{ns} /$ & i- & - & -Nshoka & - & $\rightarrow$ & i [nšoka] & [inšoka] & Snake \\
\hline 9. & /ns/ & - & bho- & -Nsue & - & $\rightarrow$ & Bo [nswe] & [ßonswe] & All \\
\hline 10. & /nj/ & - & - & ke-Ny- & $-\mathrm{a}$ & $\rightarrow$ & [kena] & [keeja] & run \\
\hline
\end{tabular}

The resemblance of the words in (f) $i$ [nčoka], (g) e [nfoka], and (h) i [nšoka] having the meaning of "snake" is the results of generic relatedness. In addition, the data shows that whenever the sound [ᄃ̌] appears in "languages" such as Kurya, Sweeta, Suba, Kine na sound [ᄃ̌ $]$ in Simbiti, Kiroobha na Kenye, it is referred as [f] in Kabwa, although all "languages" refer to a single word with the same meaning.

Generally, consonants sounds in North Mara "languages" have shown great relatedness among these "languages" because many sounds look similar in their uses in all "languages". However, there are slight differences of such sounds especially in Kabwa "language" which distinguish it a bit from other "languages". Those differences are mainly in articulation to a single word of the same meaning.

\subsection{Vowel}

A vowel phoneme is one of the human speech sounds that is produced by letting the breath flow out without closing any part of the mouth or throat (pulmonic airstream mechanism) [12]. These are voiced sounds which are produced during articulation, there is vibration of vocal cords but without the audible friction as the passes freely through the mouth [14]. This is the main difference that distinguishes the vowels from the consonants. The number of vowels in a language depends on the language itself; every language chooses the number of vowels from bowel of sounds.

The presence of a certain number of vowels in the language depends on the articulation of sounds which involves things like: position of the tongue and the mouth shape: the vowel can be high, low or back due to the position of the tongue. It can also be rounded or unrounded depending on the mouth shape. North Mara "languages have seven vowels. The vowels in these "languages" are listed below as hinted above (they are written in phonetics and normal writings)

Table 6. Vowels in Orthography and Phonetic.

\begin{tabular}{ll}
\hline Orthography & Phonetic \\
\hline $\mathrm{i}$ & {$[\mathrm{i}]$} \\
$\mathrm{e}$ & {$[\mathrm{e}]$} \\
$\mathrm{e}$ & {$[\varepsilon]$} \\
$\mathrm{a}$ & {$[\mathrm{a}]$} \\
$\mathrm{o}$ & {$[\mathrm{o}]$} \\
$\mathrm{o}$ & {$[\mathrm{o}]$} \\
$\mathrm{u}$ & {$[\mathrm{u}]$} \\
\hline
\end{tabular}

The vowels in phonetic are seven but according to orthography (normal writing) that has been used they seem to be five. The view is supported by [9] when explaining about vowel system in Bantu languages. They state that there are groups of Bantu languages which have seven vowels, those vowels phonetically are seven but in Roman orthography which is used in writing, they are five. They explain more that it is obvious that orthography writing is insufficient; it has a lot of shortcomings. The view is quite true, that is what is happening in North Mara "languages", in writing they are five but when it comes to articulation they are seven. Figure 1 show the vowels used in North Mara "languages".

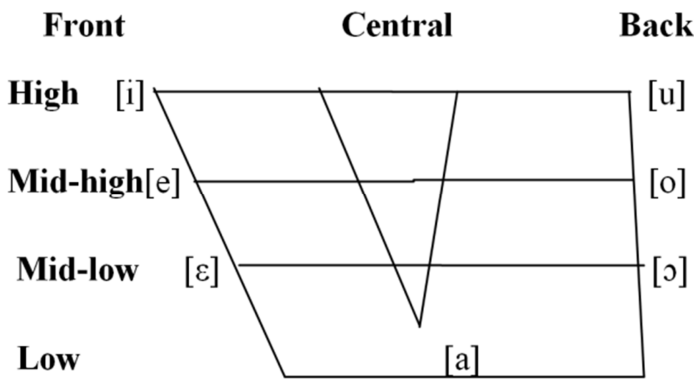

Figure 2. Vowels Trapezium in North Mara "Languages".

[i ] = high, front, unrounded.

$[\mathrm{u}]=$ high, back, rounded .

$[\mathrm{e}]=$ mid-high, front, unrounded.

$[\varepsilon]=$ mid-low, unrounded

[o] = mid-high, back, rounded.

[o] = mid-low, back, rounded.

[a] = low, unrounded.

From the data, it seems that North Mara "languages" have long vowels which appear in various situations depending on the structure of the word concerned. The view is supported by [9] as they state:

"...it is important to caution that there is another truth concerning the Bantu languages vowels which is not normally mentioned. That truth concerns the presence of long and short vowels in many Bantu languages..."

There are many words in these "languages" which have long vowels. However, the issue of long vowels incurs deficient in orthography as the issue of the number of vowels as hinted above. Many words in these "languages" are written in short vowels but they are articulated while lengthened. Observe table 7 and 8 below.

Table 7. Words in Orthography and Phonetic

\begin{tabular}{llll}
\hline "Languages" & Orthography & Phonetic & Glossary \\
\hline Kurya & tata & taata [ta:ta] & father \\
Simbiti & tata & taata [ta:ta] & father \\
Kiroobha & tata & taata [ta:ta] & father \\
Sweeta & tata & taata [ta:ta] & father \\
Kabwa & tata & taata [ta:ta] & father \\
Suba1 & tata & taata [ta:ta] & father \\
Kine & tata & taata [ta:ta] & father \\
Kenye & tata & taata [ta:ta] & father \\
\hline
\end{tabular}


Other words that show differences in orthography and phonetics to these "languages" are:

Table 8. Other Words in Orthography and Phonetic.

\begin{tabular}{lll}
\hline Orthography & Phonetic & Glossary \\
\hline kura & kuura [ku:ra] & cry \\
omonto & omonto [omo:nto] & person \\
omoro & omooro [omo:ro] & river \\
omoro & omoro [omoro] & fire \\
irino & iriino [iri:no] & tooth \\
ekera/ekyara/ikyara & ekeera [eke:ra], & finger \\
\hline
\end{tabular}

Table 8 above illustrates how the vowels appear in orthography and phonetic, being short and long vowels.

Generally, the issue of articulation seems to be controversial in North Mara "languages" as many words are written in short vowels but when pronounced they become long vowels. This does not carter all words; there are words which are pronounced the way they are written. In this sound aspect three things were compared; compensatory lengthening, deletion and minimal pairs.

\subsubsection{Compensatory Lengthening}

[7] explains that this kind of lengthening is characterized by the disaooearances of an element accompanied by the lengthening of another segment. In the collected data, the process of compensatory lengthening appeared for some words in the investigated "languages". In this process several vowels were dropped, these are back, mid, high-front and low. Moreover, some vowels were lengthened. Observe the following tables (9-15).

Table 9. Shows the lengthened vowels; $[i+e=e:]$ and $[i+i=i:]$.

\begin{tabular}{llll}
\hline "Languages" & Words & Lengthened Vowels & taimukya imwe:no \\
\hline Kurya & taimukya imwi + eno & $\rightarrow$ & ghegha emwe:no \\
Simbiti & ghegha emwe + eno & $\rightarrow$ & ghegha emwe:no \\
Kiroobha & ghegha emwe + eno & $\rightarrow$ & taimukya imwe:no \\
Sweeta & taimukya imwi + eno & $\rightarrow$ & ghegha imwi:nu \\
Kabwa & ghegha imwi + inu & $\rightarrow$ & imuka imwe:no \\
Suba1 & imuka imwi + eno & $\rightarrow$ & ghegha emwe:no \\
Kine & ghegha emwe + eno & $\rightarrow$ & imukya imwe:no \\
Kenye & imukya imwi + eno & & \\
Glossary & take one + this & & \\
\hline
\end{tabular}

Table 9 illustrates the lengthened vowels: [e:] resulted from the combination of $[i+e]$ which is similar in 7 "languages" and differ in one "language", that is Kabwa, having [i:] resulted from [i $+\mathrm{i}]$.

Table 10. Shows the lengthened vowels; $[i+o=o:],[i+u=u:]$ and $[e+o=e:]$.

\begin{tabular}{llll}
\hline "Languages" & Words & Lengthened Vowels & omona umwo:no \\
\hline Kurya & omona umwi + ono & $\rightarrow$ & omona umwo:no \\
Simbiti & omona umwi + ono & $\rightarrow$ & omona umwo:no \\
Kiroobha & omona umwi + ono & omona umwo:no \\
Sweeta & omona umwi + ono & $\rightarrow$ & omwana umwu:nu \\
Kabwa & omwana umwi + unu & $\rightarrow$ & omona umwo:no \\
Suba1 & omona umwi + ono & omona umwe:no \\
Kine & omona umwe + ono & omona umwo:no \\
Kenye & omona umwi ono & $\rightarrow$ & \\
Glossary & Child one + this & & \\
\hline
\end{tabular}

Table 10 illustrates the lengthened vowels: [o:] resulted from the combination of $[\mathrm{i}+\mathrm{o}]$ which is similar in 6 "languages" and differ in two "languages", that is Kabwa, having [u:] resulted from[i $+\mathrm{u}$ ] and Kine [e:] as a combination of [e $+\mathrm{o}]$.

Table 11. Shows the lengthened vowels; $[i+e=e:]$ and $[e+e=e:]$.

\begin{tabular}{llll}
\hline "Languages" & Words & Lengthened Vowels & \\
\hline Kurya & inswi imwi + eno & $\rightarrow$ & inswi imwe:no \\
Simbiti & inswi imwi + eno & $\rightarrow$ & inswi imwe:no \\
Kiroobha & inswi imwi + eno & $\rightarrow$ & inswi imwe:no \\
Sweeta & inswi imwi + eno & $\rightarrow$ & inswi imwe:no \\
Kabwa & enswe emo + eno & $\rightarrow$ & enswe emo eno \\
Subal & inswi emo + eno & $\rightarrow$ & inswi emo eno \\
Kine & inswi emwe + eno & $\rightarrow$ & inswi emwe:no \\
Kenye & inswi imwi + eno & $\rightarrow$ & inswi imwe:no \\
Glossary & fish one + this & & \\
\hline
\end{tabular}

Table 11 above illustrates the lengthened vowels: [e:] resulted from the combination of $[\mathrm{i}+\mathrm{e}]$ which is similar in 6 "languages". The words in two "languages", Kabwa and Suba1 have no compensatory lengthening process. 
Table 12. Shows the lengthened vowels; $[i+o=o:],[e+o=e:]$ and $[i+u=u:]$.

\begin{tabular}{llll}
\hline "Languages" & Words & & Lengthened Vowels \\
\hline Kurya & umwibhi umwi + ono & $\rightarrow$ & umwibhi umwo:no \\
Simbiti & umwibhi omwe + ono & $\rightarrow$ & umwibhi omwe:no \\
Kiroobha & umwibhi umwe + ono & $\rightarrow$ & umwibhi umwe:no \\
Sweeta & umwibhi umwi + ono & $\rightarrow$ & umwibhi umwo:no \\
Kabwa & umwibhi umwi + unu & $\rightarrow$ & umwibhi umwu:nu \\
Suba1 & umwibhi umwi + ono & $\rightarrow$ & umwibhi umwo:no \\
Kine & umwibhi umwe + ono & $\rightarrow$ & umwibhi umwe:no \\
Kenye & umwibhi umwi + ono & $\rightarrow$ & umwibhi umwo:no \\
Glossary & thief one + this & & \\
\hline
\end{tabular}

Table 12 illustrates the lengthened vowels: [o:] resulted from the combination of $[\mathrm{i}+\mathrm{o}]$ which is similar in 4 "languages"; Kurya, Sweeta, Subal and Kenye. Vowels [e:] resulted from [e + o] for Simbiti, Kiroobha and Kine and [u:] from the combination of $[i+u]$ for Kabwa only.

Table 13. Shows the lengthened vowels; [ $a+a=a:]$.

\begin{tabular}{llll}
\hline “Languages" & Words & Lengthened Vowels & \\
\hline Kurya & tang'a + amanche & $\rightarrow$ & tang'a:manche \\
Simbiti & ng'aana + amanche & $\rightarrow$ & ng'aana:manshe \\
Kiroobha & ng'aana + amanche & $\rightarrow$ & ng'aana:manshe \\
Sweeta & tang'a + amanche & $\rightarrow$ & tang'a:manche \\
Kabwa & ng'aana + amanji & $\rightarrow$ & ng'aana:manji \\
Suba1 & tang'a + amanche & $\rightarrow$ & tang'a:manche \\
Kine & tang'a + amanche & $\rightarrow$ & tang'a:manche \\
Kenye & tang'a + amanshe & $\rightarrow$ & tang'a:manshe \\
Glossary & give + water & & \\
\hline
\end{tabular}

Table 13 illustrates the lengthened vowels: [a:] resulted from the combination of $[\mathrm{a}+\mathrm{a}]$ which is similar in all "languages"

Table 14. Shows the lengthened vowels; $[i+o=o:],[e+o=e:]$ and $[e+u=e:]$.

\begin{tabular}{llll}
\hline "Languages" & Words & Lengthened Vowels & omonto umwo:no \\
\hline Kurya & omonto umwi + ono & $\rightarrow$ & omonto omwe:no \\
Simbiti & omonto omwe + ono & $\rightarrow$ & omonto umwe:no \\
Kiroobha & omonto umwe + ono & $\rightarrow$ & omonto umwo:no \\
Sweeta & omunto umwi + ono & $\rightarrow$ & omuntu ng'umwe:nu \\
Kabwa & omuntu ng'umwe + unu & $\rightarrow$ & omonto umwo:no \\
Suba1 & omonto umwi +ono & $\rightarrow$ & omonto umwe:no \\
Kine & omonto umwe + ono & $\rightarrow$ & omonto umwo:no \\
Kenye & omonto umwi ono & & \\
Glossary & Person one + this & & \\
\hline
\end{tabular}

Table 14 illustrates the lengthened vowels: [o:] resulted from the combination of $[\mathrm{i}+\mathrm{o}]$ which is similar in 4 "languages"; Kurya, Sweeta, Subal and Kenye. Vowels [e:] resulted from [e + o] for Simbiti, Kiroobha and Kine and [e:] from the combination of $[\mathrm{e}+\mathrm{u}]$ for Kabwa only.

Table 15. Shows the lengthened vowels; [e+i=e:], [e+e=e:] and $[i+i=i:]$.

\begin{tabular}{llll}
\hline "Languages" & Words & $\rightarrow$ & Lengthened Vowels \\
\hline Kurya & taimukya iyende + imwi & $\rightarrow$ & taimukya iyende:mwi \\
Simbiti & ghegha iyende + emwe & $\rightarrow$ & ghegha iyende:mwe \\
Kiroobha & ghegha iyende + emwe & $\rightarrow$ & taimukya ende:mwi \\
Sweeta & taimukya ende + imwi & ghegha iyindi:mwi \\
Kabwa & ghegha iyindi + imwi & $\rightarrow$ & taimukya ende:mwi \\
Suba1 & taimukya ende + imwi & ghegha iyende:mwe \\
Kine & ghegha iyende + emwe & $\rightarrow$ & taimukya ende:mwi \\
Kenye & taimukya ende + imwi & $\rightarrow$ & take another + one \\
Glossary & & & \\
\hline
\end{tabular}

Table 15 above illustrates the lengthened vowels: [e:] resulted from the combination of [e $+\mathrm{i}]$ which is similar in 4 "languages"; Kurya, Sweeta, Subal and Kenye. Vowels [e:] resulted from [e + e] for Simbiti, Kiroobha and Kine and [i:] from the combination of $[i+i]$ for Kabwa only.
From the given data above, it is obvious that compensatory lengthening is revealed within the investigated "languages" in several words, although in some "languages" such as Kabwa and Suba1, compensatory lengthening did not appear, observe table 11. It has revealed to other "languages" in the 
same word. The compensatory lengthening can be put in summary by showing the deleted and lengthened vowels as follows:

$$
\begin{aligned}
& \mathrm{a}+\mathrm{a} \rightarrow \mathrm{a}: \\
& \mathrm{e}+\mathrm{e} \rightarrow \mathrm{e}: \\
& i+e \rightarrow e: \\
& \mathrm{i}+\mathrm{i} \rightarrow \mathrm{i}: \\
& i+o \rightarrow o: \\
& i+u \rightarrow u: \\
& e+o \rightarrow e: \\
& e+u \rightarrow e:
\end{aligned}
$$

In this process of compensatory lengthening there are some vowels which were deleted and formed new ones that were lengthened, such vowels are [i], [o] and [u] as written in italic above. The process has covered all 8 "languages" in different words; this proves how these "languages" relate to each other. The analyzed 6 words out 7 showed similarities, this is equal to $85.7 \%$.

\subsubsection{Deletion}

[9] defines deletion as one of the phonological rules which concerns with the dropping of some sounds during articulation of morphemes which are closer. That means, the sound which was present formally disappear. [15] citing Persian languages adds that it happens under specific circumstances a sound or sounds in speech disappear some sounds become deleted through this process.

In these "languages" deletion occurred to some morphemes during the process of compensatory lengthening. Therefore, some morphemes were deleted from some words when articulating the words. Observe table 16 below:

Table 16. Deletion of Morpheme.

\begin{tabular}{llll}
\hline "Languages" & Deleted-Morpheme & & Pronounced-word \\
\hline Kurya & Maha+igha & $\rightarrow$ & maigha \\
Simbiti & Maha + igha & $\rightarrow$ & maigha \\
Kiroobha & Maha+igha & $\rightarrow$ & maigha \\
Sweeta & Maha+igha & $\rightarrow$ & maigha \\
Kabwa & Maha+igha & $\rightarrow$ & maigha \\
Suba 1 & Maha + igha & $\rightarrow$ & maigha \\
Kine & Maha + igha & $\rightarrow$ & maigha \\
Kenye & Maha + igha & $\rightarrow$ & maigha \\
Glossary & look + thiy way & & \\
\hline
\end{tabular}

Therefore, deletion of morpheme $[h a]$ in the word /maha/ is done to all "languages" of North Mara. This is also another evidence that these "languages" resemble to each other. If deletion happens to one word in one "language", it applies the same to other "languages" to the same word. This deletion is equal to $100 \%$.

\subsubsection{Minimal Pairs}

These are words with slight phonological differences that differentiate the meaning. [11] defines it as a pair of words with equal number of sounds having different in one sound that cause change of meaning; for example, /put/ and /but/. This definition, in fact concerns with sound segments only. Massamba keeps on explaining that apart from the sound segments it can also deal with supra-segmental features such as stress, tone etc, that can differentiate the meaning of words. For example, stress can cause change of meaning, /per' mit/ and /'permit/. [13] adds that minimal pair practice can be beneficial in helping language learners understand and distinguish different sounds, phonemes and achieve better pronunciation.

In Bantu languages, especially these of North Mara, minimal pairs are revealed to some words in all 8 "languages". All these pairs triggered various sound changes in these "languages". Observe the example on table 17 below:

Table 17. Hunia and Honia Minimal Pairs.

\begin{tabular}{llll}
\hline \multirow{2}{*}{ "Languages" } & \multicolumn{2}{l}{ Minimal Pairs } & \\
\cline { 2 - 4 } & Word & cordinator & Word \\
\hline Kurya & hunia & and & honia \\
Simbiti & hunia & and & honia \\
Kiroobha & hunia & and & honia \\
Sweeta & hunia & and & honia \\
Kabwa & hunia & and & honia \\
Suba1 & hunia & and & honia \\
Kine & hunia & and & honia \\
Kenye & hunia & and & honia \\
Glossary & "hunia"-push and "honia"-sale something by walking \\
\hline
\end{tabular}

The vowels that brought distinction between two words are $/ u /$ and $/ o /$ which cause the change of meaning between two words. This pair of words has appeared in all "languages". The meaning of these words is the same to all "languages". This again triggers the idea that there is great relatedness among these "languages". Observe the other example on table 18 below:

Table 18. Hita and Huta Minimal Pairs.

\begin{tabular}{llll}
\hline \multirow{2}{*}{ "Languages" } & \multicolumn{2}{l}{ Minimal Pairs } & Word \\
\cline { 2 - 4 } & Word & cordinator & huta \\
\hline Kurya & hita & and & huta \\
Simbiti & hita & and & huta \\
Kiroobha & hita & and & huta \\
Sweeta & hita & and & huta \\
Kabwa & hita & and & huta \\
Suba1 & hita & and & huta \\
Kine & hita & and & huta \\
Kenye & hita & and & \\
Glossary & hita"-remember & and "huta"-inflate \\
\hline
\end{tabular}

Distinction of words is due to vowel $/ i /$ and $/ u /$ which real cause the change of meaning between the two words. This pair of words appeared in all 8 "languages", it proves the resemblance of these "languages". Observe the other example below on table 19:

Table 19. Imuria and Imiria Minimal Pairs.

\begin{tabular}{llll}
\hline \multirow{2}{*}{ "Languages" } & Minimal Pairs & & \\
\cline { 2 - 4 } & Word & cordinator & Word \\
\hline Kurya & imuria & and & imiria \\
Simbiti & shobhurya & and & imiria \\
Kiroobha & hara & and & imiria \\
Sweeta & imuria & and & imiria \\
Kabwa & hara & and & imiria \\
Subal & imuria & and & imiria \\
Kine & imuria & and & imiria \\
Kenye & imuria & and & imiria \\
Glossary & "imuria"/shobhurya/ hara-peel and "imiria"-plant for \\
\hline
\end{tabular}


The distinction of words is caused by $/ u /$ and $/ i /$ vowels which has caused the change of meaning. In this pair there are some "languages" whose pair of words do not resemble to the pairs of other "languages". According to the data, Simbiti, Kiroobha and Kabwa look a bit different. These "languages" have only one word which resemble to other "languages" which is "imiria" and lack the other word of the pair which is similar to other "languages". Instead, they have different words, Simbiti speakers use "shobhurya", Kiroobha and Kabwa speakers use "hara" which both have the same meaning as "imuria" which is used with other "languages".

As the aim of the study was to compare the sound system in order to trace relationship of North Mara "languages", 2 out of 3 words which were compared showed that these "languages" real relate to each other. This is equal to $66.6 \%$. Figure 2 below gives the summary of various sound system categories in percentage showing the relatedness of North Mara "languages".

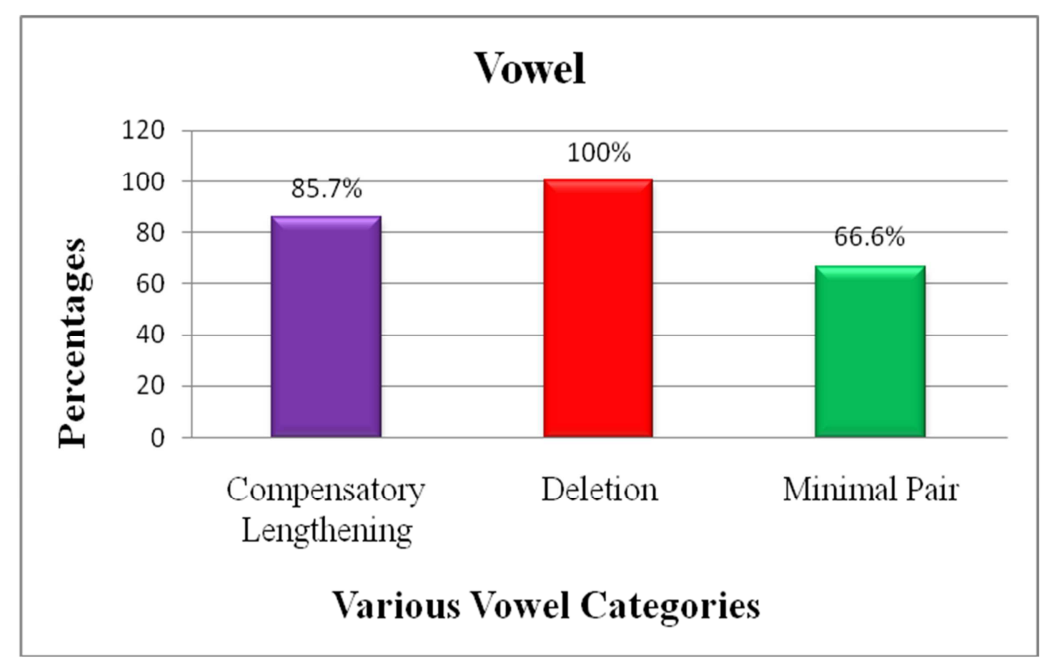

Figure 3. Showing Various Categories of Sound System in Percentage.

\section{Conclusion}

Conclusively, the article has discussed various issues concerning the sound system. The explanation about consonants has been given, through it there is a proof of the great resemblance among the "languages" of North Mara. 12 consonant sounds out of 14-16 were similar to all 8 "languages" which is equal to $85.71 \%$. Moreover the consonants which are not used by those "languages" were analyzed; these are $[1, \delta, p, \theta, v$, and $\mathrm{z}]$. The lacking of these sounds was similar to all "languages".

Additionally, various syntactic categories have been discussed, these are compensatory lengthening, where 6 words out of 7 showed the process of compensatory lengthening which is equal to $85.7 \%$. Another category was deletion which was revealed as some morphemes were deleted during the process of compensatory lengthening. The deleted morpheme carter across all "languages", the resemblance shown is equal to $100 \%$. The other category is minimal pair which appeared in these "languages". Under minimal pairs 2 words out 3 have shown similarities of the investigated "languages" which is equal to $66.6 \%$.

In general, the sound system has shown great relatedness of North Mara "languages" to the extent that one might consider them as dialects of the same language or originated from the common ancestor rather than being independent language.

\section{References}

[1] Anttila. R (1972). An Introduction to Historical and Comparative Linguistics. Universityof Califonia, Los angeles, USA: Maxmillan Publishing Co.

[2] Bubenik. V and Luraghi. S (2010). Continuum Companion to Historical Linguistics. London: Continuum International Publishing Group.

[3] Bynon. T. B (1977). Historical Linguistics. London: Cambridge University Press.

[4] Campbell. L. (1998). American Indian Languages: The Historical Linguistics ofNative America. Oxford: Oxford University Press.

[5] Chomsky. N and Morris. H (1968). Sound Pattern of English. New York. Harper andRow.

[6] Habwe. J and Karanja. P. (2004). Misingi ya Sarufi ya Kiswahili. Nairobi. Phoenix Pumblishers.

[7] Kavitskaya. D. (2002). Compensatory Lengthening: phonetics, phonology, diachrony. Doctoraldissertation. University of California, Berkley.

[8] Kihore. Y. M, Massamba. D. P. B and Msanjila. Y. P (2003). Sarufi Maumbo ya Kiswahili (Samakisa) Sekondari na Vyuo. Dar es Salaam: TUKI.

[9] Massamba. D. P. B, Kihore. Y. M and Msanjila. Y. P (2013). Fonolojia ya Kisawhili Sanifu (FOKISA): Sekondari na Vyuo. Dar es Salaam: TUKI. 
[10] Massamba. D. P. B (2011). Maendeleo Katika Nadharia ya Fonolojia. Dar es Salaam: TUKI.

[11] Massamba. D. P. B (2012). Misingi ya Fonolojia. Dar es Salaam: TUKI.

[12] Nasibu. M. K and Basil. E. B. (2016). A Handbook of English Phonetics and Phonology. Mwanza: Bagoka Publishing Company Limited.

[13] Rahimy. R and Haghighi. M. (2017). The Effect of L2 Minimal Pairs Practice on Iranian Intermediate EFL Learners'
Pronunciation Accuracy. Islamic Azad University, Tonakabon, Iran.

[14] Sayeekumar. M (2015). "The Sounds of English". Journal of English Language and Literature (JOELL). Vol. 2. Issue 4. Retrieved 23rd may, 2018 from http//www.joell.in.

[15] Veysi. E. (2016). "Description and Analysis of Phonological Processes in Dezfuli Dialect Based on the Framework of Optimality Theory". The Caspian Sea Journal. Volume 10, Issue 1, Supplement 4, 266-272. Retrieved 24th May, 2018 from http://www.csjonline.org/. 